\title{
What's in It for Me? - Peer Observation of Teaching: Experiences from a Primary School in Sweden
}

\author{
Lena Ivarsson \\ Mid Sweden University \\ Sundsvall, Sweden
}

\begin{abstract}
Peer observations of teaching, POT, is a model for developing teachers to reflect on their teaching practice and discuss their ideas with colleagues. This article contributes to the knowledge of how peer observation of teaching can be used in a primary school as a model to develop teachers' teaching practices, and highlights the challenges throughout the process. Semi-structured interviews were used for data collection and analyzed by a qualitative content analysis with a deductive approach. The results of the study confirm that peer observation of teaching is, in fact, a useful model for metacognitive improvement of teaching and learning for teachers, provided that some necessary conditions are met, for example transparency in the planning of the process, inclusion of teachers in the decision-making process, and training in the process of providing and receiving feedback.
\end{abstract}

Keywords: learning; observation; peer observation of teaching (POT); primary school; teaching.

\section{Introduction}

The goal of peer observation of teaching, POT, is to develop teachers teaching practice through personal reflection as well as through discussions with the peer observer (Cosh, 1998; Gosling, 2000). Furthermore, Cosh (1998), Fullerton (1999), Hills and Samuel (2018) and Marshall (2004) argue that POT benefits both the observed and the observer, as both will reflect upon their teaching practices, and as a result grow professionally.

Another purpose of peer observation is to sensitize teachers about their own teaching, develop their ability to talk about it, and create a larger professional learning community where teachers freely discuss their practices. By identifying and discussing teaching and learning as a natural part of everyday life in school, teachers become more aware of their own teaching habits, and can thus sieve 
through them. Naturally, as teachers enhance their practices, they become more confident in their work which then has a direct impact on their students' learning (Hammersley-Fletcher \& Orsmond 2004; Peel 2005; Swinglehurst, Russell \& Greenhalgh, 2008).

Historically, teachers in Sweden have worked with "closed doors". Only the teacher and the students knew what was going on in the classroom. Teachers rarely discussed their own teaching and thus, they did not have any bases for comparing or reflecting on their teaching practices. Today, Swedish teachers are shyly peeking through their classroom doors seeking collaborations with colleagues, discussing their insecurities and sharing their celebrations.

With this as a background, a well-functioning model to conduct peer observations is of great importance. Thus, the aim of this study is twofold: to contribute to the knowledge of peer observation of teaching and to present a model for using peer observation of teaching in a primary school. The research study attempted to answer the following two questions:

1. How can teachers use POT as a tool to develop teaching and learning?

2. What factors can facilitate POT to be used effectively?

The article continues with a literature review describing the components of peer observation of teaching as well as the benefits and challenges according to earlier research, followed by empirical starting points, results, and lastly, discussion including didactic implications and concluding remarks.

\section{Literature Review}

This part consists of an overview of the model for peer observations used, and benefits and challenges with peer observations.

\subsection{Contextual Framework}

Swedish schools are guided by a national curriculum. The responsibility for schools is on local authorities who decide on school organization and implementation of learning standards. The standards for each subject define the teaching goals. The work in the schools is a process of constantly moving towards sustainable ways to meet and evaluate the standards and improve the teaching practices. That process led to a trend among teachers to reflect on their own teaching styles and habits in order to achieve the standards and raise student learning outcomes. 
However, Swedish teachers are not used to observe and be observed as well as receive and provide feedback. Furthermore, there is no tradition in Sweden for teacher evaluation and accountability. Still, they believe they are professionals and to continue to grow in their professionalism and leadership skills, communication and reflection are essential for a practitioner (Steinberg, 2013).

Thus, POT will provide that missing link between teacher practices and selfreflection prompted by teacher peer review and feedback. More than that, positive reviews and suggestions for improvement from colleagues will add to teachers' feeling of credibility and raise self-confidence (Bernstein, 2008).

Several studies of peer observations (Allern, Sundset \& Sandvoll, 2017; Bell \& Mladenivic, 2008; Torres, Lopes, Valente \& Mouraz, 2017) seem to have been conducted in university settings, therefore, this study can be seen as a complement to those studies, and provide research from a primary school.

Marshall (2004, p. 187) defines and explains the power of POT as follows:

\begin{abstract}
"The power of peer observation resides in its developmental and collegial orientation and its exposure of colleagues to affirmation, constructive criticism, and the experience of how others teach differently. In such a situation, the teachers working together all learn from each other. Indeed, in peer observation of classroom teaching, it is often the case that the observer learns at least as much as the observed. Peer observation is more about mutual peer learning, and is not a matter simply of the observed learning from the observer."
\end{abstract}

Thus, POT is a tool to help teachers enhance the quality of teaching and learning by both reflecting on their own teaching and add to the teaching of others (Hammersley-Fletcher \& Orsmond, 2004; Peel, 2005). This process can ultimately improve the teaching and learning climate in a school adding to its transparency and collaborative decision making (Gosling, 2000). One of the major components of POT is the visibility and openness of its design and implementation. Typically, POT contains of three parts, a pre-observation meeting, an actual observation, and a post-observation meeting (HammersleyFletcher \& Orsmond, 2004). The pre-observation meeting enables colleagues to meet and jointly plan the observation. Teachers agree on the time, place, the content of observation and the type of feedback provided. The model implies that the observers position themselves in an appropriate part of the classroom, where they observe and take notes about agreed upon parts of the lesson. The post-observation meeting should be given ample time and take place within a week from the observation. The earlier the follow-up meeting occurs, the more the observer and the observed will be able to recall. The feedback should be constructive and focused on what components worked well and what ideas 
could be improved. As a result, the observed reflects upon the feedback and attempt to make the changes suggested. While going through the process, teachers need to keep in mind the big picture, namely, that through collaboration and mutual observation and reflection, they are engaged in a lifelong learning as professionals (Peel, 2005).

In the following two sections, literature review about the benefits and challenges of implementation of POT will be discussed.

\subsection{Benefits of Peer Observation of Teaching}

According to Bell (2002), POT is beneficial if conducted under supportive conditions. Well planned POT, where teachers are fully informed and in agreement with the process they are involved, provides a good basis for successful implementation. It is also critical that the principal and other administration in charge is supportive and allow for flexible scheduling needed for the observations (Bell \& Mladenivic, 2008).

Through POT the relationship between teaching and learning becomes visible for all participants (Peel,2005; Swinglehurst, Russell \& Greenhalgh, 2008). Through the observations, formative feedback is generated as qualitative evidence of teaching practices. This evidence is a starting point for self-reflection and professional growth (Bell \& Mladenivic, 2008; Swinglehurst et.al., 2008). Furthermore, the feedback enables teachers to develop and change their teaching habits in a sustainable manner (Bell \& Mladenivic, 2008; Swinglehurst et.al., 2008; Taylor \&Tyler, 2012). In their study Torres et.al. (2017) found that the observers tended to compare observed teaching with their own teaching, and used this knew knowledge to develop their own teaching strategies. Lastly, POT facilitates establishing supportive relations among colleagues (Peel, 2005). Hopefully, an open climate based on peer observation further establishes discussions among colleagues and becomes an integral part of a school culture (Beck, D'Elia, Lamond, 2014; Hammersley-Fletcher \& Orsmond 2004).

\subsection{Challenges in implementation of Peer Observation of Teaching}

According to Siddiqui, Jonas-Dwyer and Carr (2007), teachers find it difficult to allocate the time needed for POT. They mention busy workloads, lack of time needed for planning and lack of clarity about the aim of the observations. In addition, in order for POT to be helpful for both the observer and the observed, all parties involved should have an open and positive attitude throughout the process (Beck, D’Elia, Lamond, 2014; Hammersley-Fletcher \& Orsmond, 2004). Teachers also need to feel well prepared to be able to accept constructive criticism and informed on how to give feedback in a respectful way (Siddiqui et.al., 2007). Researchers warn that POT may be misunderstood and thus cause scrutiny, criticism, feelings of intrusive and challenge with overtones inspection and judgment (Hills \& Samuel, 2018; Siddiqui et.al. „, 2007; Lomas \& Nicholls 2005; Marshall, 2004). To overcome the challenges of implementation of POT, 
significant time needs to be allotted for planning, for modelling open and transparent communication, and setting clear expectations.

\section{Empirical points of departure}

This section begins with a short description of the project, within which the study was conducted, followed by the implementation design, data collection procedure, and analysis of data.

\subsection{The Project Setting}

The study was conducted in a primary school in the northern part of Sweden. The project was one of the components of a regional research project called "the best regional educational system in the world". The goals of the overall project were to increase student achievement at grade level standards, develop capacity for leadership among teachers and initiate collaborations with local companies (www.miun.se).

The school consisted of 150 students and 20 teachers. It is located in an area with a mobile population, where it is common place for families to frequently move in and out of the community. Teachers, however, have been retained and some of them have been teaching in the school for more than ten years.

The POT project was funded by local companies and continued for three years to ensure its sustainability (2012-2015).

\subsection{Implementation design}

The principal of the school together with the school management team were inspired to try POT after reading Steinberg's (2013) book on peer observations. In his book, Steinberg describes how to use peer observation in the classroom to improve teaching practices more generally and teachers' leadership in the classroom, more specifically. Steinberg's book focuses on different areas to observe, for example, leadership, democracy and participation, metacognition and the beginning of lessons. Every chapter has a user guide helping teachers to reflect on the different areas. The principal suggested the idea of using peer observations to the teachers. Most of the feedback from the teachers was positive and the suggestion was accepted.

A total of three different observations were carried out for every teacher. The management team, which consisted of the principal and special education teachers, assigned the teacher observation pairs and designed an observation protocol. The first observation focused on the introduction and the summary parts of lessons. The observation protocol looked at the first minutes of a lesson (preparation, methods, structure, interest and motivation), the end of a lesson (structure, conclusion, expectations for the next time), and the student-teacher 
relationship throughout the lesson (mutual respect, trusting attitude, adaptation to the student, group and situation/lesson, communication with the students).

New teacher pairs were assigned for the second observation which focused on the teachers as leaders in the classroom. The observer was asked to focus on how the observed acted as a leader rather than what the person did. This was a way to shed light on how one's own behavior affect's students' behavior. Lastly, a new teacher pair configuration was created for the third observation. For the third observation, Steinberg's book chapters were selected by the principal and distributed to all teacher pairs to model.

\subsection{Data collection procedure}

The researcher chose semi-structured interviews to collect the data. Semistructured interviews enable participants to answer the same questions, and at the same time, to elaborate on their answers in a more personal fashion. The general questions facilitate comparability, analysis and reporting, while the more personal answers reveal deeper descriptions as an interesting complement (Bryman, 2011). The semi-structured questions compared to structured interview questions allow for flexibility in following thoughts and understanding perceptions (Patton, 1990). The interview question aimed at capturing the teachers' experiences of using peer observations as a way to develop their teaching practice. Questions asked were for example, Were you involved in the planning of using POT? How did you feel about trying POT? How did you experience being the observer as well as being observed?

Approximately fifteen teachers, who had participated in peer observations of teaching, were invited to take part in the interviews, but only five of them agreed. All five teachers had taken part in six teacher pair observations, three as the observer and three as the observed. The semi-structured interviews were conducted individually, in the teachers' classrooms after school. The interviews were recorded and lasted from 30 to 60 minutes each. The teachers in the study agreed upon taking part in the interview and they were informed that they could chose to end the interview whenever they wanted. They were also informed that the data collected was processed in such a way that anonymity was guaranteed (Codex.vr.se, 2019).

\subsection{Analysis of data}

A qualitative content analysis with a deductive approach was used to systematize and review data from the semi-structured interviews (Cavanagh, 1997; Elo \& Kyngäs, 2008; Hsiu-Fang \& Shannon, 2005). An unstructured matrix for categorization was used in the study as it allows data to be categorized both in the main categories and in sub-categories (see Table.1). The interviews were transcribed and coded in themes according to the three main components that constitute the process of peer observation of teaching, namely: pre-observation (planning, teacher expectations, and foci of observations), the actual observation 
(the experience of the observer and the observed), and post-observation (feedback, implications). The categories identified were prerequisites, experiences, and outcomes.

An example of the meaning units illustrating subcategories are shown in Table 1.

Table 1: Examples of the meaning units illustrating subcategories

\begin{tabular}{|c|c|c|}
\hline Category & Subcategory & Meaning unit \\
\hline Prerequisites & $\begin{array}{l}\text { planning, teacher } \\
\text { expectations, } \\
\text { foci of } \\
\text { observations }\end{array}$ & $\begin{array}{l}\text { We did not take part in the planning process, } \\
\text { but we had all agreed to try observations. }\end{array}$ \\
\hline Experiences & $\begin{array}{l}\text { experience of } \\
\text { the observer } \\
\text { experience of } \\
\text { the observed }\end{array}$ & $\begin{array}{l}\text { I was quite nervous that } \\
\text { somebody was going to observe me. }\end{array}$ \\
\hline Outcome & $\begin{array}{l}\text { feedback } \\
\text { implications for } \\
\text { one's classroom }\end{array}$ & $\begin{array}{l}\text { It's difficult to separate the teaching from the } \\
\text { teacher, so it's easy to take criticism personal. }\end{array}$ \\
\hline
\end{tabular}

\section{Results of analysis of data by category}

The result will be presented under the main headings: pre-observation meeting, the actual observation, and post-observation meeting, in an attempt to highlight the various parts in peer observation of teaching.

\subsection{Pre-observation meeting}

The pre-observation meeting aims to give the observer and the observed time to plan the actual observation, for example where, when and how the observation will take place and how feedback will be given.

\subsubsection{The decision to introduce POT}

All participants in the interview communicated that the principal together with the management team came up with the idea to try POT. The teachers concurred they were involved in the process of decision, illustrated by this teacher's remark:

"I experienced that all teachers were involved in the decision, if we had said no, there had not been any observations. We were more or less unanimous to try POT." (C) 
Even though teachers agreed to try peer observations they did not feel they were guided and prepared to perform them. More than that, the observation protocol provided, although helpful, was not very meaningful because the teachers did not have any input in creating it.

\subsubsection{Teacher expectations}

The five participants in the interview study expressed positive feelings about the opportunity to try POT. At the same time most of them admitted they had been uneasy, for POT was something new for them, and they did not have any experience or knowledge about it. Here is how one of the teachers recalls how she felt about being observed:

"I was quite nervous when I knew that somebody was going to observe me. As a teacher you are your own tool, in a way. At the same time, I thought it would be exciting, having somebody observing me and giving me constructive feedback." (A)

Furthermore, two of the participants expressed concerns about their lack of preparation to communicate any critical feedback.

"It sounded interesting but at the same time I asked myself if I would be able to give and take both positive and negative feedback. I mostly thought about giving negative feedback, how it would be received, or what would happen if we only gave positive feedback." (D)

The other three participants expressed curiosity and saw POT as a possible way to make themselves visible as leaders, as well as an opportunity to share their ways of teaching with colleagues.

"I think we need to open up the doors and help each other. We need to think about POT as a way to help each other and make visible what we do really good and what we need to develop." (E)

\subsubsection{Decisions about foci of observations}

Teacher commented that the suggestion from the principal and the management team about the focus of the first observation made sense and was very thoughtful, namely, to begin the peer observation with a topic that was not too sensitive (the beginning and ending of a lesson).

However, teachers disagreed on the foci of the other two observations they felt they needed to be involved in the decision-making process. That was especially evident, as teachers pointed out, in the setup of the last peer observation. Teachers were provided with chapters of Steinberg's book and directed to model 
their observations according to the methods described in the chapters. For example, two of the chapters were titled, "How do I adjust my leadership in the classroom to the level of maturity of my students?", and "How to avoid negotiations with students about their behavior." Teachers felt unprepared to base their comments on the models presented in the book.

\subsection{The actual observation}

This section describes teachers experiences of being observed and being the observer.

\subsubsection{The Experience of Being Observed}

Participants associated the experience of being observed with a variety of emotions. They felt apprehensive as well as excited. Some of the teachers stated they put extra effort in the teaching preparation because of the observation session. Here is how one of the teachers remembers it:

"I was nervous, and I think that was rather naturally. I could feel that I wanted to perform well, I tried to be a bit more organized, but I didn't use more time for planning." (A)

Teachers commented that having an observer in the classroom did not affect their students as they were accustomed to many adults in the classroom on a daily basis.

"We are used to being many adults in the classroom, working together, but we are not used to being observed." (D)

Most of the teachers mentioned that they would have preferred to have been involved in the process of selecting their observers. They were convinced that being observed by a teacher they had a close relation to, would provide more productive discussions and on a deeper level.

"I have had different observers every time. I think it would be good to have the same observer, if one is to work more systematically with observations. Working in pairs and getting comfortable with each other may have a positive impact on the discussions." (B)

\subsubsection{The Experience of the Observer}

Observing colleagues was perceived as both stimulating and challenging. Teachers felt stimulated as that gave them the opportunity to observe a colleague in action and take part in a colleague's work in the classroom. Teachers shared that observing a colleague gave new thoughts and dimensions to their own teaching. They felt invigorated to have the time to sit down and observe a colleague, to take notes about what happened in the classroom, and then have an opportunity to discuss it with the teacher. 
"You think you know each other rather well, but you don't know much about your colleagues' behavior in the classroom. I have seen few of my colleagues"in action", but it was inspiring. I found myself getting into a state where I just admired and collected good examples, instead of focusing on observing to be able to give useful feedback." (A)

Observing, however, was also perceived as challenging because the participants felt they lacked the necessary skills and experiences needed. Although they had a protocol to fill in, which was expressed as helpful, they didn't always find it easy to fit what they saw into the form. Some of the participants, during the observation, tried to focus on finding moments that would lead to a good discussion afterwards instead of focusing on the topic of observation. They recognized that was due to lack of experience and they suggested that some preparation was required.

\subsection{Post-observation meeting}

During the post-observation meeting the observer gives feedback to the observed. They have time to discuss both the benefits and the challenges observed.

\subsubsection{Feedback}

The participants felt there was a need for teachers to take the time and discuss the components of the lesson, the strategies used in the delivery of the material, student difficulties in learning the topic, and other issues that came up during the lessons that teachers felt were more important than the focus of the observation. However, the time of 30 minutes allotted for the follow-up meetings did not allow for deeper discussions. Some participants even reported being interrupted during the follow-up meeting by students or teachers, as something had happened that immediately needed to be sorted out.

Another difficult part in providing feedback, that teachers struggled with, was when less then positive comments were communicated. In fact, all participants stated that they avoided talking about anything that might be perceived as negative feedback.

"It's sensitive. I do not know how I would react to negative criticism. It's difficult to separate the teaching profession and the person so it is easy to take criticism personally." (A)

The participants expressed a need for practice and training on how to give and receive productive feedback in various forms. 


\title{
4.3.2 What's in it for me?
}

Teachers were surprised at the variety of issues they observed in classrooms other than the strategies of teaching they were supposed to look at. They noticed students' behavior, students' attitudes toward different tasks, the ability of students to work in groups, teachers' abilities to call attention, and other ways they could incorporate in their own teaching. Other teachers' teaching inspired them and made them want to answer the question "What's in it for me?" As one teacher commented:

\begin{abstract}
"As an observer you see a lot of what's going on in the classroom. Activities that is not clear or visible for the teacher. Things happen between the students, for example. I observed students who looked like they were taking part in teaching but who actually did something totally different. If I notice this in a classroom as an observer, it's likely that it also occurs in my own classroom. By being aware about this I can try to identify these students in my own classroom." (B)
\end{abstract}

It is important to note that the POT is a process and the process starts with teachers identifying themselves in other teachers' classrooms. Teachers commented that it was difficult for them to focus on the task assigned by the management team because they found other more relevant ideas to look at. Participants suggested they wanted to have an opportunity to discuss with each other issues pertinent to them.

\section{Discussion}

In this section the researcher will focus on the benefits and challenges of peer observations of teaching according to the participants in the study. For the teachers, for POT to be effective, one of the most important components needs to be transparency in the planning of the process. Then, inclusion of teachers in the decision-making process is imperative. Lastly, training in the process of providing and receiving feedback has to be part of the peer observation implementation in order to achieve its goals.

Earlier research (Bell, 2002; Bell \& Mladenivic, 2008; Siddiqui, Jonas-Dwyer \& Carr, 2007) confirms the results from the present study, namely, that planning, transparency and inclusion of all participants in the decision-making process, is critical both for the implementation and the outcomes of the observations. The participants in the study were convinced that the shortcoming of the process could have been prevented by better planning and openness of discussion prior to its implementation (Beck, D'Elia, Lamond, 2014; Hammersley-Fletcher \& Osmond, 2007).

The results of the study also confirmed that time needs to be allotted for planning, implementation and follow-up meetings for sustainable changes to 
occur (Siddiqui, Jonas-Dwyer \& Carr, 2007). Teachers in this study had no time for preparation and only 30 minutes for the post-observation-meeting. Participants believed that if the method is to make a difference and actually lead to improvements, more time is needed to be devoted to reflections, discussions, and follow-up questions.

An interesting issue raised by the study was the selection of the teacher pairs. Participants suggested careful consideration of the pairs for future studies. The participants argued that pairs should be familiar with each other to feel safe in discussing observations. Participants also noted that forming new pairs for each observation made deeper discussions about teaching and learning almost impossible, and that fixed pairs are desirable in future peer observations.

Another visible challenge was the fear and uncertainty in giving and receiving feedback. A number of researchers have also discussed the same problem (Hammersley-Fletcher \& Orsmond, 2004; Lomas \& Nicholls, 2005; Marshall, 2004; Siddiqui, Jonas-Dwyer \& Carr, 2007) According to Hammersley-Fletcher \& Orsmond (2004) an open and positive attitude to critically discuss teaching and learning is needed for a productive discussion. Both the observer and the observed, have to feel comfortable providing and receiving feedback in the form of comments, suggestions or highlighting areas of improvement. Participants argued that it would have been extremely helpful if training, modeling, or some role-playing exercises were provided prior to the POT.

Lastly, we need to mention that the results are focused on individual reflections and not of the implication of the model to the school culture. In addition, no evidence was collected to check for impact on teaching and learning in the classroom.

\subsection{Method discussion}

Semi-structured interviews were used for the data collection, as they allow to ask all participants the same questions but at the same time, adjusting to each participant. Only five out of fifteen teachers agreed upon taking part in the interview, which gives a small number of participants, although the results are aligned with other, similar studies. Observations of the peer observations of teaching together with semi-structured interviews could, possibly, have provided a broader basis for analysis. Although, the results from the study gives a picture of the benefits and the challenges with peer observations of teaching.

\subsection{Didactic implications and concluding remarks}

The study conducted showed that POT can be a useful tool for teachers to get an insight into their own teaching practices. More than that, peer observations can be used as a starting point for discussions among teachers about various issues that arise in the day to day experiences in the classroom. Furthermore, POT can be used to build a climate of self-reflection, cooperation, safety of expression, and sharing of ideas. Lastly, peer observations and follow-up discussions will 
positively affect personal dimensions such as confidence, professionalism, and identity of teachers as learners.

The study also highlighted the critical components that need to be present for the POT-process to be productive and effective. Recommendations for future studies are derived from those components, from the limitations of the study, and from the challenges encountered or pointed out by the participants:

a. Bigger sample of teachers needs to be identified for interviews.

b. The POT-process needs to be followed for a longer period of time in order to see its impact on school culture.

c. Teachers need to be trained in providing and receiving feedback.

d. Teachers are to be included in the decision-making process of the design of the POT, in selection of the teacher pairs and the focus of the observations.

e. Teachers should participate and modify the discussion protocol as needed.

f. Additional time needs to be allotted for the post-observation meetings as needed.

Overall, the participants interviewed in the study, deemed the process extremely helpful and worth continuing. They believed that if incorporated in a better way, it can change the daily work of the school and create a professional learning community made of reflective practitioners.

\section{References}

Allern, M., Sundset, M.A., \& Sandvoll, R. (2017). Peer observation of teaching asmotivation for educational development - from teaching as private enterprise to a collective approach. The $2^{\text {nd }}$ EuroSoTL conference, June 8-9, 2017, Lund, Sweden.

Beck, C., D'Elia, P., \& Lamond, M. W. (2014). Easy and effective professional development: The power of Peer observation to improve teaching. New York: Routledge. https://doi.org/10.4324/9781315776200

Bell, M. (2002). Peer observation of teaching in Australia, paper for LTSN Generic centre. Available online at: http://www.josctechdis.ac.uk/assets/Documents/resources/Peer_observation of_teaching_in_australia.pdf

Bell, A., \& Mladenivic, R. (2008). The benefits of peer observation of teaching for tutor development. Journal of higher education, 55, 735-752. https://doi.org/10.1007/s10734-007-9093-1

Bernstein, D. (2008). Peer review and evaluation of the intellectual work of teaching. Change Magazine, March/April, 48-51. https://doi.org/10.3200/chng.40.2.48-51

Bryman, A. (2011). Samhällsvetenskapliga metoder. (Social research methods). Malmö: Liber $\mathrm{AB}$.

Cavanagh, S. (1997). Content analysis: concepts, methods and applications. Nurse researcher, 4, 5-13. https://doi.org/10.7748/nr1997.04.4.3.5.c5869 Codex.vr.se, 2019, retrieved 2019-03-11. 
Cosh, J. (1998). Peer observation of higher education - a reflective approach. Innovations in education and training international, 35, 171-176. https://doi.org/10.1080/1355800980350211

Elo, S., \& Kyngäs, H. (2008). The qualitative content analysis process. Journal of Advanced Nursing, 62(1), 107-115. https://doi.org/10.1111/j.1365-2648.2007.04569.x

Fullerton, H. (1999). Observation of teaching. In A handbook for teaching and learning in higher education (eds. H. Fry. S, Ketteridge, \& S. Marshall) pp. 220-234. London: Kogan page.

Gosling, D. (2000). Guidelines for peer observation of learning and teaching. Available at: http://dera.ioe.ac.uk/13069/

Hammersley-Fletcher, L., \& Orsmond, P. (2004). Evaluating our peers: is peer observation a meaningful process?. Studies in higher education, 29, 489-503. https://doi.org/10.1080/0307507042000236380

Hills, J. D., \& Samuel, P. (2018). Collaborating to raise standards: A brief practical guide to peer observation (Master of teaching). Independently published.

Hsiu-Fang, H., \& Shannon, S. E. (2005). Three approaches to qualitative content analysis. Qualitative health research, 15, 1277-1288. https://doi.org/10.1177/1049732305276687

Lomas, L., \& Nicholls, G. (2005). Enhancing teaching quality through peer review of teaching. Quality In higher education, 11, 137-149. https://doi.org/10.1080/13538320500175118

Marshall, B. (2004). Learning from the academy: From peer observation of teaching to peer Enhancement of learning and teaching. Journal of adult theological education, 1, 185-204.https://doi.org/10.1558/jate.1.2.185.65573 miun.se/motmittuniversitetet/samverkan/run/Arkiv/mnu/, retrieved 2019-04-14.

Patton, M. Q. (1990). Qualitative research and evaluation methods. UK: Sage Publications Ltd.

Peel, D. (2005). Peer observation as a transformatory tool? Teaching in higher education, 10, 489-504. https://doi.org/10.1080/13562510500239125

Siddiqui, Z. S., Jonas-Dwyer, D., \& Carr, S. E. (2007). Twelve tips for peer observation of $\begin{array}{llll}\text { teaching. } & \text { Medical 297-300. }\end{array}$ https://doi.org/10.1080/01421590701291451

Steinberg, J. (2013). Ledarskap I klassrummet: handbok för arbetsro och effektivt lärande. Stockholm: Gothia Fortbildning. [Leadership in the classroom: handbook for peaceful working conditions and effective learning].

Swinglehurst, D., Russell, J., \& Greenhalgh, T. (2008). Peer observation of teaching in the online Environment: an action research approach. Journal of computer assisted learning, 24, 383-393. https://doi.org/10.1111/j.1365-2729.2007.00274.x

Taylor, E.S., \& Tyler, J.H. (2012). The effect of evaluation on teacher performance.

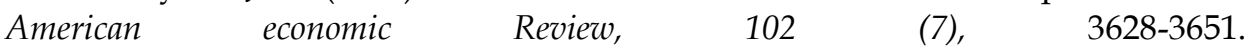
https://doi.org/10.1257/aer.102.7.3628

Torres, A.C., Lopes, A., Valente, J.M.S., \& Mouraz, A. (2017). What cathches eye in class observation? Observers' perspectives in a multidisciplinary peer observation of teaching program. Teaching in higher education, oct2017, vol.22, issue 7. https://doi.org/10.1080/13562517.2017.1301907 